\title{
W05-03
}

\section{SPIRITUAL COPING, COMMUNICATION TRAINING AND PROBLEM SOLVING FOR SCHIZOPHRENIA}

\section{N. Tuchman}

Department of Psychology, University of Miami, Miami, USA

This speaker will describe literature regarding the adaptive uses of religion and spirituality, such as religious or spiritual coping and making meaning from stressful life events. She will cover the Spiritual Coping module of the Culturally-Informed Therapy for Schizophrenia (CIT-S). In this phase, therapists begin with a detailed spiritual history in order to gauge each family member's beliefs, involvement in spiritual or religious activities and other practices they may have. Therapists assign homework that encourages the family members to explore their religious or spiritual experience in a positive and adaptive light. For clients who do not identify as religious or who are experiencing religious delusions, therapists proceed with this phase of treatment with a more philosophical or existential approach to spirituality and morality. A demonstration of this module will be conducted using volunteers from the audience.

This speaker will also describe the final two modules of CIT-S, which are based on the work of Falloon etal. (1984) and Miklowitz and Goldstein (1997). The fourth phase of treatment, Communication Training, attempts to unite concepts and skills learned in the three previous phases through specific attention to communication skills. Family members learn to communicate with and support each other in effective ways. The fifth phase of treatment, Problem-Solving, allows the family to learn and practice problem-solving strategies using relevant examples. 